\title{
Programme Structure and Academic Freedom: An Analysis of the "New Programme" in Architecture at the University of Toronto $1968-1983$
}

\author{
JULIA ANTONIA EASTMAN*
}

\begin{abstract}
The degree of autonomy available to an individual professor depends upon thenature of the academic programme(s) to which he or she contributes. Some programmes communicate information to students by means of discrete classes, and leave to the students the task of integrating this information into a unified body of knowledge. Most undergraduate programmes in the liberal arts and sciences fall into this category. The primary mechanism for coordinating the teaching activity of faculty members is the curriculum: within its framework, professors enjoy substantial autonomy in the design and provision of their individual classes. In contrast, a second type of academic programme seeks to shape the way students understand and approach the world. Realization of this objective necessitates the development of extensive and complex mechanisms for communication and coordination, and constrains the autonomy of individual professors. The "New Programme" in architecture at the University of Toronto-although of this second type - was without mechanisms capable of producing concerted action and common standards. The problems which plagued the department of architecture for more than a decade and culminated in a recommendation for its closure, are traced to this failure.
\end{abstract}

\section{RÉSUMÉ}

L'autonomie que peut exercer un professeur donné dépend du caractère du programme académique auquel il contribue. Certains programmes communiquent des informations aux étudiants par le moyen de classes distinctes et laissent aux étudiants eux-mêmes la tâche d'intégrer ces informations en un système de connaissances. Cela est le cas de la plupart des programmes sousgradués en arts et en sciences. Le mécanisme principal qui coordonne l'enseignement de professeurs est le programme d'études: dans ce cadre les professeurs ont une autonomie importante dans le développement et la présentation de leurs cours spécifiques. 
Par contre, d'autres programmes académiques ont comme objectif de former la façon dont les étudiants conçoivent et adressent le monde. La réalisation de cet objectif exige le développement de mécanismes complexes et larges pour la communication et la coordination, et restreint l'autonomie de chaque professeur. Le "New Programme" en architecture à l'Université de Toronto, quoiqu'étant du second type, n'avait pas les mécanismes nécessaires pour résulter en une action concertée et en jugements communs. Les problèmes qui ont accablé le département d'architecture pour plus d'une décennie et qui menèrent à une recommandation pour sa clôture, ont leurs origines dans cette omission.

Late in February 1986, the Provost of the University of Toronto recommended to its Governing Council closure of the Faculty of Architecture and Landscape Architecture. The reasons given for the recommendation were: that the Faculty required an infusion of several million dollars for the continued viability of its programmes; that in the University's straitened financial circumstances, any such infusion would be at the expense of the budgets of other units or of other institutional priorities; and that - owing to the existence of longstanding problems within the Faculty - it was unclear that additional resources would in fact assure the future soundness of its programmes. Justification for a transfer of resources to the Faculty of Architecture and Landscape Architecture was therefore deemed to be lacking: closure of the Faculty was presented as the only acceptable alternative (University of Toronto [U. of T.], 1986, February 20, p. i).

It was widely known on campus, and implicitly acknowledged by the administration ("Administration presents", 1986, February 24, pp. 1-2), that most of the longstanding problems cited by the Provost involved the programme in architecture (rather than that in landscape architecture). Allegations by students of bias in evaluation and ideological totalitarianism; increasingly frequent complaints to the University Ombudsman; dissension within the faculty; inadequate space; rapid turnover of administrative staff; increasingly critical external reviews; and repeated reorganization had characterized the architecture programme for more than ten years. In an editorial entitled "Anarchi-tecture: What is really going on in our University's Faculty of Architecture and, better yet, when is it going to be over?", the student newspaper, The Varsity, had once described Architecture as "the Beirut of U of T politics" (1984, January 20, p. 4) - reflecting a widespread belief that the programme was not so much beset by problems, as prey to a syndrome of escalating conflict.

Several months after the Provost's recommendation for closure, the future of the programme in architecture remains uncertain. This paper does not pretend to explain the chain of events which led to its present predicament. Rather, it seeks to show why a pedagogical approach such as that adopted by the (then) Department of Architecture in the late 1960s might give rise to the type of problems exhibited by the programme, given the norms prevailing within the university, and the state of the architectural profession at the time. 


\section{The Information-Processing Challenge posed by the "New Programme"}

A premise of organizational design is that the information-processing (i.e. communication and coordination) requirements of an organization are a function of the uncertainty of its task. As Galbraith (1974) has explained;

[T] he greater the uncertainty of the task, the greater the amount of information that has to be processed between decision-makers during the execution of the task. If the task is well understood prior to performing it, much of the activity can be pre-planned. If it is not understood, then during the actual task execution more knowledge is acquired which leads to changes in resource allocations, schedules, and priorities. All these changes require informationprocessing during task performance. Therefore the greater task uncertainty, the greater the amount of information that must be processed among decisionmakers during task execution in order to achieve a given level of task performance. (p. 28)

Like an effective organization, a Faculty or department requires informationprocessing capacity congruent with the uncertainty of its task. Two of the factors which influence the extent of this uncertainty are the breadth of the unit's programme and the nature of its pedagogical objectives.

The breadth of programmes of architectural education is a function of the interdisciplinary nature of the profession. In order to integrate knowledge of technical, environmental, aesthetic, social scientific and other fields into a coherent programme, a department of architecture must have greater informationprocessing capacity than most other professional or disciplinary schools.

In most cases, 'integration' of information from different fields into an academic programme in fact involves identification by faculty of the pertinent information, and its presentation to students in the form of discrete classes. It is actually the students who must integrate the information presented to them into a unified body of knowledge (Bess, 1982, p. 72). Most academic programmes thus require little communication among faculty following the curriculum design phase. The actual communication to students of an integrated body of knowledge is a much more uncertain task. A programme which conceives of its task in this light seeks (not simply to present pertinent information to students, and let them make of it what they will, but) to bring about a specific change in the way the student understands and approaches the world. It thus confronts uncertainty arising not only from the diversity of its constituent disciplines, but also from the differing abilities and personalities of the students. The latter is particularly pronounced if - as is true of many vocational programmes - students have had little exposure to the field prior to admission.

The objectives of the "New Programme" adopted in 1968 by the University of Toronto's Department of Architecture were those of an integrated programme. According to a graduate (Boulard, 1983):

The New Programme set out to dismantle the traditional structure of university architectural education - based on the lecture, the practical class and the design studio - and claimed to re-assemble the necessary content in the form of the "Core Problem". Within the Core Problem, a design project was to be 
understood as an "open-ended probe". There were no longer to be the usual mandatory lectures on matters of technology, history, theory, and design methods, nor practical classes in drawing and presentation methods. Instead, it was claimed that the student, as he progressed through one year-long design project, would at certain points in the project realize his need for certain kinds of information. (p. 67)

The change from a traditional to an integrated programme increases the level of uncertainty which exists concerning the nature and timing of each professor's contribution to the education of the students. This becomes a function - not of a curriculum specified in advance and which varies little from year to year - but of the students' need for and ability to absorb the information in question. Professors' contributions to the programme must therefore be much more closely coordinated than in the traditional course-based format.

The integrated programme also embodies more complex expectations of students than its traditional counterpart. The latter's objective is to communicate quite specific information to students by means of courses: students are therefore evaluated on their mastery of the material 'covered' in each class, according to criteria established (relatively independently) by the responsible professor. The integrated programme strives, in contrast, to teach students a way of understanding and approaching the world. The complex nature of this goal gives rise to uncertainty about performance evaluation. It not only entails difficult methodological problems, but also raises potentially awkward questions about the mission of the discipline or profession. Departments seeking to offer integrated programmes must thus be capable, not only of coordinating their members' activities much more closely than do other units, but of achieving consensus concerning educational goals and measures of progress.

\section{Coordination and Consensus within an Integrated Programme}

According to Galbraith (1974), the three basic mechanisms for coordinating activity within organizations are: rules and programmes; hierarchy; and targets or goals. As was noted above, most academic programmes rely heavily on the first of these mechanisms: teaching is coordinated by means of the curriculum. A consequence is that professors have little capacity to respond to student needs or demands for instruction other than that called for by the curriculum. This constraint is potentially frustrating for professors seeking to communicate knowledge of a particular subject in a course-based programme. It is probably unacceptable to faculty seeking to ensure that students have assimilated and are able to utilize a body of knowledge. Faculty members in an integrated programme will therefore tend to turn to mechanisms other than rules and programmes to coordinate their activity.

Although a ubiquitous means of coordinating and monitoring performance of a common task hierarchy is minimal within the academic community. The reason for this - noted above - is that tasks are generally defined as individual rather than collective: professors direct their own research and conduct their classes within the 
limits prescribed by the curriculum. Professional schools are exceptions insofar as they are required, not only to expose students to specific areas of knowledge, but also to prepare them for particular roles - i.e. insofar as they are collectively responsible to society for producing a specific 'product'. It is thus not surprising that they exhibit more hierarchy than do their non-professional counterparts (Dressel, Johnson and Marcus, 1970, pp. 76-77; Lawless, 1983, pp. 139-142; Smart and Montgomery (Eds.), 1976). Since faculty members offering an integrated programme not only define their task as common (i.e. bringing about a specific change in the student's understanding of, and approach to, the world), but eschew the curriculum as a source of coordination, one might expect that they would rely on hierarchy to a greater extent than does the professional school. Whether or not this is in fact a viable option will depend on the nature of the discipline or profession in question and, in particular, on whether resort to hierarchy for educational purposes would adversely affect the ability of faculty members to succeed in their research and/or creative endeavours. If both teaching and research are collective tasks (as may be the case in a professional school dedicated to meeting quite specific social needs), hierarchy is a viable means of coordination: if, however, teaching is a collective task, but research is not (as in the political science department which offers a programme in public administration), hierarchy may limit the researcher's autonomy and thereby impede the pursuit of knowledge. In other words, the generation of knowledge and/or creative pursuits may necessitate that professors have a degree of freedom incompatible with an educational hierarchy, in which case, alternative means of coordination must be sought.

Whether or not an integrated programme in architecture can be coordinated through hierarchy is essentially a question of definition - specifically, of whether architecture is defined as art or scholarship, or as service. If architecture professors regard their role as the application of sophisticated technical skills to problems and tasks specified by others, they will require less autonomy than colleagues who are artists or scholars. It will be possible to assess the quality of their work in terms of the extent to which it satisfies external demands. Professional excellence is therefore likely to be respected and rewarded, regardless of a professor's place in the educational hierarchy. The architect as artist or scholar must, in contrast, be free to define and pursue his or her own goals - a freedom which may be threatened by hierarchy. Owing to the lack of objective measures of artistic or academic quality, authority bestowed on a chairman or programme director for the purpose of coordinating the educational programme may be used to enshrine a particular artistic or scholarly perspective. Hierarchy is therefore unlikely to be the primary coordinating mechanism in a school of architecture dedicated more to art or scholarship than to service.

This orientation would appear to have characterized most (if not all) North American architectural schools, since they disassociated themselves from the faculties of engineering in which most of them developed (Draper, 1977, p. 217). It certainly characterized the Department of Architecture at the Univerity of Toronto 
in the 1960s. Of Galbraith's three basic coordinating mechanisms, it would thus appear that only goals and targets were appropriate for the New Programme. One might well doubt that the information-processing requirements of an integrated programme could ever be met primarily by shared goals and targets. The history of Beaux-Arts architectural education in the United States suggests that perhaps they could. This form of education was modeled after the Ecole Nationale et Spéciale des Beaux-Arts in Paris, but offered by university departments rather than through ateliers (Draper, 1977, p. 217). Like the New Programme, it embodied an integrative approach to education. According to Joseph Esherick (1977):

One of the most highly developed aspects of architectural education before the

Second War was the degree to which all course work, both academic and technical, was coordinated to support the studio effort in design. The program was essentially single-minded, focused, and continuous. ... As John F. Harbeson put it, "The purpose of [the Beaux-Arts] training is to impart to each student a method of attacking and studying any problem in architectural design which may be presented". (p. 243)

It was the predominant approach to architectural education in the United States from the late 1800 s until the 1940 s. What enabled university departments to offer integrated programmes in architecture for so long? Esherick's (1977) comparison of American architectural education in the 1930s and 1970s suggests that the existence of a common ideology may have been an important factor:

It would appear to me that the greatest contrasts are, on the one hand, the insistence in the thirties that architecture's primary alliance was with art, and in the seventies that the alliance is with the social sciences; and, on the other hand, the belief in the thirties that design and designing were central and that everything else could and would be picked up by the student on his own as needed, possibly later, and the implicit belief in the seventies that it is perhaps quite the other way around and that it is design and designing that will be picked up.... And this brings us to what is perhaps the greatest contrast: that there was in the thirties a relatively consistent and homogeneous, if not exactly monolithic, point of view. ... Today the situation is one of enormous diversity, which I can only regard as healthy. (p. 275)

This suggests that to succeed in its aims - aims strikingly similar to those of its American counterparts more than thirty years before - Toronto's Department of Architecture would have required a common conception of the goals and nature of an architectural education. This would have assisted Department members to cope with the two major types of uncertainty to which integrated programmes give rise. First, it would have suggested a common direction for their educational efforts and how their individual contributions to the programme should be linked - i.e. served a coordinating function. Secondly, it would have dispelled uncertainty concerning the standards towards which students should strive.

The New Programme did embody a clear conception or ideology of architectural education, but it was not espoused by all Department members and therefore did not equip them to cope effectively with uncertainty. The programme's origins in fact militated against consensus within the Department. Members of a professional school may derive a conception of the nature of their task from a number of sources 
- their profession; institutional tradition; the administration; an academic leader in their midst; or by achieving consensus amongst themselves. Each has different implications for the constellation of support for/opposition to the resulting programme, and for the probability and shape of attempts at reform.

The New Programme was the product of an exercise of academic leadership by a newcomer to Toronto's Department of Architecture, at a time when the latter was without a clear sense of direction. The conception of architecture which had informed Departmental activity in earlier years was perceived to be inadequate, but an alternative had not yet been found. The heterogeneous profession provided no guidance, and the vision of a faculty of environmental design articulated by the then Dean had failed to capture the imagination of faculty members (U. of T., 1986, February 20, p. A:1).

By all accounts, the professor to whom the New Programme is credited possessed considerable charisma (Freedman, 1983, February 19, p. E9) - both in the popular sense of the term, and as defined by Etzioni as "the ability of an actor to exercise diffuse and intensive influence over the normative (ideological) orientations of other actors" (House, 1977, p. 191). This is significant because the personal characteristics generally associated with charismatic leadership - extremely high levels of self-confidence, dominance, and strong conviction of the moral righteousness of one's beliefs (House, 1977, p. 193) - are inimical to collegiality and compromise. It was therefore unlikely that objections to the adoption of the New Programme, or differences of opinion arising subsequently, would be accomodated through the negotiation and introduction of modifications. The stage was set for polarization.

Although some faculty members were apparently opposed to the New Programme from the outset (U. of T., 1986, February 20, pp. A:1-3), consensus concerning its merits appears to have been relatively great in its early years. The creator of the programme has been quoted (Freedman, 1983, February 19) as saying that:

One of the weaknesses of the program is you had to be dedicated to the idea of it to work in it. At the beginning, everybody was. As time went on, new people came in who weren't inducted into it and they were left to their own devices. When you've got something going and new people come in, you forget you have to explain the situation. (p. E9)

It is difficult to say whether - as this quotation suggests - commonality of perspective might have been preserved through better socialization of new members, or whether it would inevitably have succumbed to the diversity which had come to characterize the profession. In any case, succumb it did - with the result that the faculty was bereft of mechanisms for coping with the uncertainty posed by its integrative approach to architectural education.

\section{Consequences of Inability to Cope with Uncertainty}

According to Galbraith (1974), an organization which is unable to cope with the uncertainty confronting it has three basic options: to increase its capacity to 
process information; to reduce its need to process information; or to allow performance to deteriorate (p. 28). The strategy adopted by the Department of Architecture might be (loosely) characterized as a combination of the second and third of these options: management of uncertainty was left to the students. Specifically, students were made responsible for coordinating professors' and other input into the programme - i.e., for seeking out the information they required from faculty (then known as "resource persons") and other sources. This was explicit. According to the "Third Year Procedures" for the academic year 1979-80 (U. of T., 1979, October 1):

Students are responsible for contact with staff. In general terms half of our afternoon studio time will be spent in group sessions. The other half amounts to about 20 hours of staff time per week. From this you can judge what your share might be. (p. 1)

The implications and consequences of this policy account for many of the complaints voiced about the Department.

One of its implications was that the amount a student learned depended primarily, not on his or her ability to assimilate information presented by faculty, in traditional programmes, but on his or her motivation, assertiveness and commitment to the programme. It was thus desirable to admit students on the basis of criteria different from those employed by other departments and programmes giving rise to complaints from students, other sectors of the university, and the profession about subjectivity and bias in the admissions process. According to a petition submitted to the Vice-Provost on June 17, 1983 and signed by almost half the students in architecture (reproduced in U. of T., 1984, May 18):

The admission standards have attempted to favour individuals tending toward the incumbent pedagogy or who are specifically unformed. The interview process helps effect this screening, with prospective students frequently being intimidated or insulted as well. Individuals considering application to the school have been advised on occasion by other students to submit work of a non-architectural nature: portfolios are judged by criteria which appear to reject evidence of architectural ability. (p. 24)

Since the amount and nature of the material a student learned in the New Programme was a function of his or her motivation, assertiveness and interests, rather than of a curriculum, the significance of receipt of a bachelor's degree in architecture from the University of Toronto was ambiguous. Prospective employers, for example, would not have been able to assume that graduates of the Toronto programme would have been exposed to, and to some degree assimilated, a common body of knowledge. One of the primary functions of modern educational organizations is widely believed to be 'credentialing' - i.e. signalling to institutions and society at large that particular individuals have acquired a specific set of accomplishments. The Department of Architecture appears to have consciously rejected this role. Its statement to the Presidential Advisory Committee on the Structure of the Faculty of Architecture, Urban and Regional Planning and 
Landscape Architecture (cited in "Presidential Committee", 1971, January 14) asserted that:

[A]rchitecture, both as an academic discipline and as a profession, is in a quandary. Architecture, with so many other disciplines, is in danger of following concepts (whether from expediency or from fashion) that deny human values except those of marketplace efficiency. ...[Our] ambition has led us away from most of the thoughts and programs currently being pursued by schools and profession. In short, because of our convictions, we are out on a limb. (p. 2)

The Department's unwillingness to tailor its programme to the needs and demands of consumers of architectural services may in part explain the friction which has long characterized its relations with the profession (Freedman, 1983, February 19, p. E9). In the terminology of organizational behaviour, it was an instance of deliberate maladaptation on the part of an organization to its environment.

Giving students responsibility for what they learned conflicted not only with the demands of the marketplace, but also with university norms, implicit and explicit. Although many faculty members might admit to giving a disproportionate amount of attention to 'bright' students, the prevailing ethos is that one should be even-handed in assisting one's students to learn. Insofar as the policy of the Department of Architecture militated against equitable treatment of students, it might well have been repugnant to the university at large.

An explicit policy of the University of Toronto is that professional schools shall, wherever possible, draw upon the disciplinary expertise of other faculties (U. of T., 1986, February 20, p. B:44). This is always difficult for schools which take an integrative approach to education, because of the differences between the structures of their programmes and the course-based ones of other faculties. Most such schools nevertheless manage to work out arrangements with other units, or to acquire expertise which they are lacking. This coordinating function is one of which students are obviously incapable. Even if they had perceived the deficiencies of the New Programme in technical areas, architecture students would have been unable to obtain access to the expertise which the faculty lacked. The Department not only isolated itself from other faculties by adopting an integrated programme, but also abdicated responsibility for compensating (by means of hiring or service teaching arrangements) for its deficiencies.

The capacity of the students to coordinate the elements of architectural education was thus necessarily imperfect. It was nevertheless greater than their ability to cope with the second type of uncertainty generated by an integrative approach to education - that which surrounds performance goals and standards. This form of uncertainty will be more pronounced in some integrated programmes than in others. In experimental disciplines, for example, reality-testing guides behaviour. In professions defined by service, success involves meeting needs or demands. Standards of performance therefore exist independently of agreement on a common ideology or paradigm. This was not the case of architecture in the 
1960s. Lack of consensus among members of the Department of Architecture meant that uncertainty prevailed concerning the nature of the work which students should strive to produce.

The result appears to have been that a tendency - latent in all highly 'non-routine' areas in which individuals are closely identified with their work - to assess people based on their personal qualities and beliefs, rather than on the nature or outcomes of their work, was particularly pronounced within the Department. In a draft memorandum entitled "Towards a Contract for Assessment" (U. of T., 1973, September 24), the then Chairman of the Department explained that:

Architecture, like everything else, reflects the values of its creators and so assessment should deal with our values as they can be manifested through our work. What we are trying to do then, it seems to me, is to articulate those values we admire in people (and, therefore architects, and ultimately, buildings). The immediate reward is a degree. ... The values then that I can admire can, for the start, conveniently be taken from Bertrand Russell. They are vitality, courage, sensitivity and intelligence. I believe they are manifested in architecture just as they are in any other aspect of life. The work you undertake in a Core Problem will inevitably reveal your character when looked at in these lights. (p. 1)

There is reason to believe that ambiguity concerning performance criteria gave way to conflicting criteria as ideological divisions emerged and deepened within the faculty. In a report on a Third Year Group Study in October 1981 (reproduced in Excerpts, 1985), a student described the effect this had on students.

Two nights before the presentation to the class with considerable work to be done to complete the thesis, [a senior professor, not in charge of the class] begins a long discussion at [a student's] desk. Most members of the group were present. He suggested that what we were doing was wrong. ...At this point all work on the old thesis stopped. The next day... a group meeting was sharply divided about the new thesis. Six of eight members chose to do no more work on the old thesis. At dinner on this last night it was discussed that not finishing the project would make [the instructor] look bad. The presentation was thrown together and concluded the half-done work of the first proposal and a few unheard [sic] ideas from the new [senior professor's] drawings. This is an example of how within the school of Architecture the professors do not have a basic respect for the work of their colleagues. They undermine the work of each other and in so doing confuse and damage their students.

Added to the students' confusion about standards of quality, was uncertainty about the extent to which they were deemed to be attaining them, for evaluation was relatively infrequent and letter grades had been abolished. Under the circumstances, it is not surprising that the Department's approach to evaluation and feedback was the object of increasing criticism from students, university committees, and professional bodies.

In sum, the architectural faculty coped with neither of the forms of uncertainty created by an integrative pedagogical approach. Responsibility for coping with uncertainty concerning the coordination of inputs into the programme was delegated to the students. This appears to have been a relatively effective solution 
to the problem, although it had the effects of narrowing the breadth of the programme and alienating important external sectors. Department members also failed to agree on a common ideology or paradigm which would have mitigated uncertainty concerning educational goals and standards. The literature on the behavioural consequences of uncertainty suggests that this failure may account, both for the fear and hostility which characterized relations within the Department (Freedman, 1983, February 19, p. E9; U. of T., 1984, May 18, p. 20), and for the precariousness of its future.

\section{Uncertainty and the Salience of Power}

The suggestion that the absence of a common ideology gave rise to the problems besetting the Department of Architecture may well be greeted with skepticism: surely shared ideology is not necessary for the viability of academic programmes and departments! What about academic freedom?! The response is that intellectual diversity is successfully accommodated in most departments and programmes precisely because - as was noted early in this paper - tasks are defined so as to make faculty members relatively autonomous. Traditional academic programmes require only that professors agree on a curriculum, and on a basic set of groundrules governing the classroom. Within these limits, professors enjoy considerable freedom to teach what they believe to be important, in the manner they deem best. This freedom is protected by strong norms against interference in the teaching of others.

The integrated programme, in contrast, requires that faculty members agree, not only on educational objectives, standards and priorities, but also on what should be taught. Decisions which, in the traditional programme, are delegated to professors with relevant expertise, are subject to approval by the faculty as a whole.

In the absence of a common ideology, the integrated programme therefore gives rise to the conditions - uncertainty, interdependence and scarcity (Pfeffer, 1981, p. 69) - which necessitate the use of power in decision-making. Unlike its traditional counterpart (which is actually a loose federation of miniature programmes (courses)), it really is one programme. The professor who objects to aspects of the programme must either participate in something of which he or she disapproves, or seek to change it. If - as at Toronto's Department of Architecture - a spirit of compromise is lacking, the stage is set for struggle between groups of faculty with different viewpoints, for control of the programme. David Brown (1978) has summarized findings concerning the dynamics of horizontal intergroup conflict:

Conflict between groups produces mutual negative stereotyping, as group perceptions of each other become increasingly unfavourable (Sherif, 1966). Those stereotypes contribute over time to losing sight of similarities and interdependencies between the groups, and to an emphasis on their differences and conflicts of interest (Deutsch, 1973). As group boundaries become less permeable to information inputs and outputs, the amount of communication between groups decreases and the extent to which those communications are 
received with distrust or distortion increases (Blake and Mouton, 1961; Sherif, 1966). Distorted communications and negative stereotypes promote the use of militant representatives (Blake and Mouton, 1961), and aggressive actions against the other group (Deutsch, 1973). These ingredients in interaction have a self-reinforcing quality: Aggressive behaviour by one group confirms the distrust and stereotypes of the other, and legitimates their counteraggression, which in turn justifies counter-counteraggression in a vicious cycle (Deutsch, 1973). (p. 163)

In light of the integrated nature of the New Programme in architecture, the uncompromising nature of its proponents, and the disagreement which emerged within the faculty, it is not surprising that the Department of Architecture Review [Friedland] Committee (U. of T., 1984, May 18) reported that:

One ingredient...that [was] lacking was common civility or good manners towards the ideas and character of others. There was ideological intolerance uncommon in a University environment. This surprised us. It is an odd recommendation for a Committee to make, but we nevertheless make it: staff - and students - should consciously try to be more civil towards each other and to deal with the others' ideas on an intellectual rather than a personal basis. The social structure that is important in any institution seems to have broken down. (p. 20)

This breakdown accounted for the Department's 'ungovernable' character: as divisions deepened, it became increasingly difficult for administrators to maintain credibility with both factions. It was almost inevitable that, sooner or later, an administrator, however careful, would be perceived to favour one of the Department's factions, and therefore be discredited by the other. Administrative resignations followed each other in rapid succession.

The breakdown in relations within the faculty also affected the students. It did so, not only because (as illustrated above) it created confusion concerning standards, but also because the students' position of parity on the Faculty Council made them a souce of power. Of all the means - support of the administration or the profession, control of administrative positions, expertise or other resources - a group of faculty might employ to gain control of the programme, control of the students was one of the most important. It was therefore almost inevitable that the students be subject to pressure to ally themselves with one group of professors or another, and that divisions within the faculty pervade the entire school. According to the student petition presented to the Vice-Provost on June 17, 1983 (and reproduced in $U$. of T., 1984, May 18):

Within the political structure of the Department, student parity, while not problematic in and of itself, tends to reinforce the already-established ideology, since dissenting students have been driven away and tend not to engage in the school's politics. Thus elections for student positions, frequently held without advance notice, come to be dominated by students who subscribe to the ideology. Once on the committees, students' views are compromised by staff who have the power to pass or fail them. (p. 24)

The authors of the petition went on to say that:

[T] here exists an ambiguous relationship between the student and staff as "resource person". The student's progress depends entirely on her or his own 
initiative, with staff taking responsibility for little or no input while placing impossibly high demands for output. ... Evaluations by staff are infrequent, vague at best, and more often than not reflect the staff member's own biases: the student is encouraged to rely primarily on her or his own assessment of progress. At the year's end, however, only the staff are involved in the final grading, which is extremely subjective and tantamount to an unequivocal pass or fail. (p. 24)

The pretence that faculty and students were peers engaged in open-ended exploration of architectural questions was the 'big lie' at the root of the New Programme. The faculty's prerogative to pass or fail in fact gave it more power over students than is exercised by professors in traditional programmes. The latter independently assess different aspects of the student's performance. Their power is therefore dispersed. The structure of integrated programmes, in contrast, often calls for one or a small number of professors to assess all aspects of a student's performance over the course of an entire year. This structure may also preclude students from taking classes in other departments or faculties. Power of decision-making concerning the academic careers of students in integrated programmes is thus concentrated in very few hands.

In connection with the demise of another integrative approach to architectural education - Beaux-Arts training in the United States - Esherick (1977) offered this observation:

Today the situation [of architectural education] is one of enormous [intellectual] diversity, which I can only regard as healthy. The only danger I see is that one or some combination of the emerging new directions may consolidate and solidify a particular direction in such a way as to seek to dominate the scene with a monolithic structure. We would then be back where we were. If we get there I can only hope that the men in charge will be as intelligent, as cultured, as responsible as their Beaux-Arts predecessors. (p. 275)

The integrated structure of the New Programme made it inevitable that Department members would seek to make it a 'monolithic structure': their unwillingness to compromise, coupled with the inability of either faction to achieve control, made it unlikely that the power of the faculty would be exercised in a responsible manner.

One of the consequences of the absence of clear performance standards, noted above, was that the focus of assessment tends to gravitate from the nature and outcomes of performance to the personal qualities of the individuals involved. According to one graduate of the Department (Boulard, 1983):

Within the rhetoric of the New Programme, it became extremely difficult, if not impossible, to attribute deficiencies in a student's work to anything other than his own shortcomings. ...[I]n countless...extempore monologues in reviews of student work, the switch was made by sophistic sleight-of-hand from the discussion of the discipline of Architecture to the discussion of character. Many students willingly accepted this. (p. 68)

In doing so they empowered the faculty, not only to assess their work or architectural talent, but to judge their worth as people. The reason for students' acquiescence in this exercise of power may have been that - uncertain of what 
type of work or performance would lead to success in the programme - they could but attempt to appeal to the professors. The fact that students repeatedly alleged favouritism and bias in grading within the Department attests to their belief that success in the architectural programme was a function of personal affinity with the professors.

Students reacted to their extreme dependence on the faculty with petitions, protests, complaints to the Ombudsman, and appeals to the administration. It was in many respects a classic response to powerlessness. According to Brown (1978):

Power differences influence the process of interaction between upper [the faculty] and lower [the students] groups in ways that heighten the level of tension and increase the likelihood of explosive outbursts of conflict. Lower groups protect themselves by not communicating freely about their dissatisfactions to upper groups. ... Without credible information upper groups must plan on the basis of attributions about the lower groups. ... Ignorant upper groups may overreact to 'irrational' and 'unreasonable' eruptions of longsuppressed discontent from lower groups. Such overreactions serve to confirm lower group suspicions, thus fueling escalating conflict. ... These escalating consequences are not endless. Conflict that continues to escalate eventually culminates in decisive victory for one party or exhaustion for both. (p. 174)

According to the recent statements of members of the Department of Architecture to Committees of the University of Toronto's Governing Council (U. of T., 1986, April 5; U. of T., 1986, April 8), victory - short-lived though it may prove to be was achieved by students and faculty members opposed to the New Programme. This is plausible: a new "pluralistic" curriculum was after all introduced in 1983, and it is said to enjoy the support of the student body, the part-time faculty and most of the tenured professors (U. of T., 1986, April 5, p.10). This victory was nevertheless sufficiently precarious that the failure in the fall of 1985 of a search for a new Dean of Architecture and Landscape Architecture prompted the resignation of the Chairman of Architecture, the withdrawal from the programme of a number of part-time members of faculty, and a boycott of classes by students. Faculty members who had persevered in the hope that a new Dean would consolidate the new curriculum apparently gave up when that hope did not materialize, raising the spectre of the reintroduction of elements of the New Programme, and thereby setting off another round of student protest. This activity - portrayed to the Committees of the University's Governing Council as the expression of support for the new curriculum (U. of T., 1986, April 5, p.10) appeared to people outside the Faculty simply as continued internal turmoil.

The failure of these resignations and protests to communicate the intended message to the central administration - and the consequences of this failure - lend support to Pfeffer's (1981) finding that "subunits have an advantage in the political struggle that occurs within organizations if they have a consensually-shared (within the subunit), easily articulated and understood position and perspective" (p. 122). Consensus enables subunit members to advocate common interests in clear and consistent ways.

The existence of a relationship between the degree of consensus within a subunit and the extent of its power was borne out in studies of university departments by 
Lodahl and Gordon, and Pfeffer and Moore. Departments with highly developed paradigms were more successful in acquiring resources than their less cohesive counterparts (Pfeffer, 1981, pp. 122-124). House (1984) noted that, "subunit member consensus may thus be viewed as a variable that determines the degree to which the objective determinants of subunit power will be translated into actual power with other subunits. ...That is, under conditions where subunit membership is in consensus with respect to a particular issue, the full force of the structural determinants as bases of power can be exploited by the members" (p. 14). The divisions among members of the Department of Architecture appear to have been so deep as to have obscured their common interests. Resources (such as the support of students, alumni, and the profession) which might have been translated into power within the University, were instead committed to internal struggle for control. The fact that the members of the Department did not submit a unanimous brief to the Governing Council Committees considering the Provost's recent recommendation for closure suggests that not even the current threat to their Faculty's existence eclipses their differences.

\section{Power, Freedom, and the Structure of Academic Programmes}

The structure of integrated educational programmes bestows on the faculty great power over students. If professors are able to agree on the aims, content and standards of the programme, they can use this power in such a way as to truly transform the attitudes, and develop the abilities, of their students. The faculty/ student relationship assumes an intensity and focus, virtually impossible to achieve in a traditional programme. The accounts of faculty and students suggest that in the early years of the New Programme, the Department of Architecture at the University of Toronto was characterized by a spirit of intellectual passion and discovery, rare in an undergraduate programme.

Effective integrated programmes are nevertheless totalitarian. The uncertainty which surrounds the coordination of professors' activity and the establishment of standards generally cannot be resolved by reference to rules, or by administrative authority. Agreement on these matters is therefore necessary for programmatic integrity. Such agreement often arises naturally out of a common disciplinary paradigm, conception of professional service, institutional tradition or other source. Where this is not the case, the nature of integrated programmes demands that consensus be achieved or dissent suppressed. If neither course succeeds, conflict ensues. The negation of academic freedom and demeaning of the students is its eventual result.

What are the alternatives? The only way to preserve the faculty/student relationship characteristic of the integrated programme, while preserving academic freedom and providing standards, would be to subdivide the programme - to transform it into a series of ateliers. Professors would be free to teach their students as they thought best, and the latter - while heavily dependent on one individual - would be confronted with a single, consistent set of performance demands. The atelier arrangement is of course possible only if individual 
professors can teach all, or most, of the knowledge and skills the students require.

The only other option is fragmentation and de-coupling of the programme - in other words, a return to the traditional format. The latter is much criticized for the 'cafeteria-style' education it provides. Critics argue that - to prolong the analogy momentarily - faculty members should pay attention to the nature of the meal as well as to the qualities of each individual dish. The above analysis suggests that in a climate of gastronomical pluralism, too much attention to the meal would be unwise. The implications for university education are depressing. It seems that when professors attempt to respond collectively to the educational needs of their students, they are prone to impinge upon each other's freedom. There appears to be an unfortunate trade-off between the freedom which faculty members individually enjoy, and the coherence and responsiveness of the programmes which they collectively provide.

\section{REFERENCES}

Administration presents rationale for plan to close architecture faculty. (1986, February 24). University of Toronto Bulletin, 39(13), pp. 1-2.

Anarchi-tecture. (1984, January 20). The Varsity, 104(44), p. 4.

Bess, J. L. (1982). University organization: A matrix analysis of the academic professions. New York: Human Sciences Press.

Boulard, P. (1983, Summer). Architectural education and its double: The New Programme 1968-1982 at the University of Toronto. The Fifth Column, 3(3/4), pp. 67-69.

Brown, L. D. (1978). Toward a theory of power and intergroup relations. In C. A. Cooper and C. P. Alderfer (Eds.), Advances in experimental social processes (Vol. 1). London: Wiley.

Draper, J. (1977). The Ecole des Beaux-Arts and the architectural profession in the United States: The case of John Galen Howard. In S. Kostof (Ed.), The Architect (pp. 209-237). New York: Oxford University.

Dressel, P. L., Johnson, F. C. \& Marcus, P. M. (1970). The confidence crisis: An analysis of university departments. San Francisco: Jossey-Bass.

Esherick, J. (1977). Architectural education in the thirties and seventies: A personal view. In S. Kostof (Ed.), The Architect (pp. 238-279). New York: Oxford University.

Freedman, A. (1983, February 19). The passion of Peter Prangnell. The Globe and Mail, p. E9.

Galbraith, J. R. (1974). Organizational design: An information-processing view. Interface, 4, pp. 28-36.

House, R. J. (1977). A 1976 theory of charismatic leadership. In J. G. Hunt and L. L. Larson (Eds.), Leadership: The cutting edge (pp. 189-207). Carbondale, IL: Southern Illinois University Press.

House, R. J. (1984, December). Power in organizations: a social psychological perspective. Unpublished manuscript. Faculty of Management Studies, University of Toronto.

Institutions in the city: Group study in October 1981: Third year. In Excerpts from the A.S.U. sources of documents for the School of Architecture and Landscape Architecture, University of Toronto, 1979 to 1985. (Available from the Architecture Students' Union, University of Toronto).

Lawless, D. J. (1983). Organizational structure and basic units in higher education institutions International Journal of Institutional Management in Higher Education, 7(2), pp. 137-147. 
Programme Structure and Academic Freedom: An Analysis of the "New Programme" in 29 Architecture at the University of Toronto 1968-1983

Pfeffer, J. (1981). Power in organizations. Marshfield, MA: Pitman.

Presidential committee studies architecture faculty structure. (1971, January 14). University of Toronto Bulletin, 24(12), p. 2.

Smart, J. C. \& Montgomery, J. R. (Eds.). (1976). Examining departmental management. (New directions for institutional research, No. 10, Summer 1976). San Francisco: Jossey-Bass.

University of Toronto, Department of Architecture. (1973, September 24). Fourth year: Core problem IV: Towards a contract for assessment (Draft). In Excerpts from the A.S.U. sources of documents for the School of Architecture and Landscape Architecture, University of Toronto, 1979 to 1985. (Available from the Architecture Students' Union, University of Toronto).

University of Toronto, School of Architecture. (1979, October 1). Third year procedures: 1979/80 session. In Excerpts from the A.S.U. sources of documents for the School of Architecture and Landscape Architecture, University of Toronto, 1979 to 1985. (Available from the Architecture Students' Union).

University of Toronto. (1984, May 18). Report of the Department of Architecture Review [Friedland] Committee.

University of Toronto, Office of the Provost. (1986, February 20). Recommendation for closure of the Faculty of Architecture and Landscape Architecture.

University of Toronto, Governing Council. (1986, April 5). Report number 239 of the Academic Affairs Committee and report number 175 of the Planning and Resources Committee (Minutes).

University of Toronto, Governing Council. (1986, April 8). Report number 240 of the Academic Affairs Committee and report number 176 of the Planning and Resources Committee (Minutes). 